\section{Metastasis of Prostate Cancer to Pleura}

\section{Shantanu Singh* and Ashish Singh}

Henderson Pulmonary and Sleep Medicine, 568 Ruin Creek Road, Suite 127, Henderson, NC 27536, USA

\begin{abstract}
Prostate cancer is the most common type of malignancy in males in many parts of the world. Prostate adenocarcinoma is both second leading cause of cancer and cancer death in the North American males. Of the patients who are detected with prostate cancer, about $10-20 \%$ of them are found to have metastatic cancer on presentation. Prostate cancer commonly metastasizes to the bones; vertebrae, ribs, long bones and the skull.

Metastasis to pleura is extremely uncommon. We present a case of prostate cancer metastasizing to pleura. The purpose of this report is to remind physicians of this rare occurrence. This case also highlights that pleural fluid cytology can be negative repeatedly even though pleural surface has multiple metastatic nodules.
\end{abstract}

Keywords: Prostate cancer; Pleural metastasis; Pleural effusion; Video assisted thoracoscopic surgery; Thoracoscopy

\section{Key Message}

The purpose of this report is to remind busy practicing physicians to keep pleural metastasis in the differential diagnosis in a patient with history of Prostate Cancer who presents with pleural effusions even if repeated pleural fluid cytology are negative. When index of suspicion is high in such patients, thoracoscopy can be done to establish the diagnosis.

\section{Case Report}

A 70 year old Caucasian male who had undergone surgery and radiation therapy for prostate adenocarcinoma five years ago, presented with worsening shortness of breath and cough of several weeks duration. Physical examination showed decreased breath sounds over right lower lung field. Chest X-Ray (CXR) showed right lower lobe

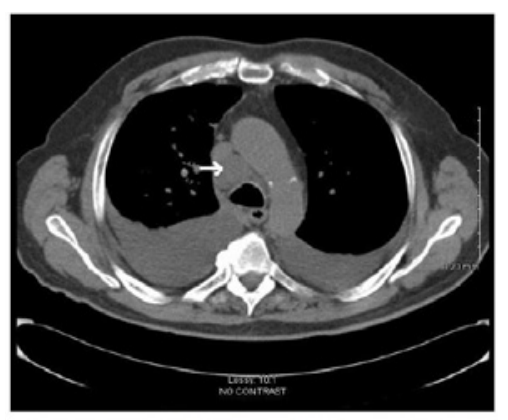

Figure 1: CT scan of chest. White arrow showing Mediastinal lymphadenopathy.

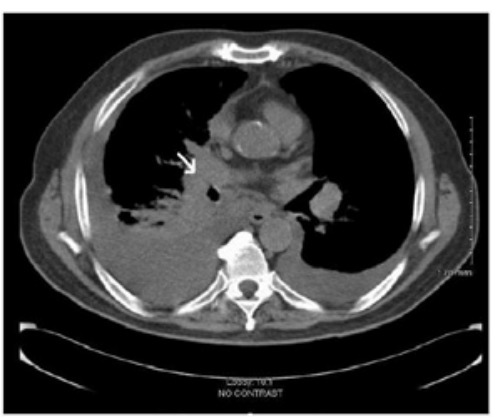

Figure 2: CT scan of chest. White arrow Showing Right Hilar Mass. infiltrate suspicious for pneumonia and small right pleural effusion. Treatment for pneumonia was started.

Patient's symptoms worsened despite treatment for pneumonia. CXR showed an increase in the pleural effusion. A diagnostic and therapeutic thoracentesis was done with removal of $1500 \mathrm{cc}$ of straw colored fluid. Fluid analysis showed it to be transudate and cytology was negative. CT chest showed mediastinal adenopathy (Figure 1), right hilar mass (Figure 2) suspicious for primary lung carcinoma with metastases, right pleural effusion and near complete consolidation of right lower lobe (Figure 3). Bronchoscopy showed widened right minor hilum and irregular bronchial mucosa in the bronchus intermedius but no discrete endobronchial mass. Endobronchial biopsies from these areas showed small atypical cells with marked crushing artifact with features of neuroendocrine tumor. Re-biopsy was recommended.

During this time, patient was also having frequent re-accumulation of right pleural effusion requiring thoracentesis with removal of about 1000 to $1500 \mathrm{cc}$ of fluid each time every 3-7 days for a total

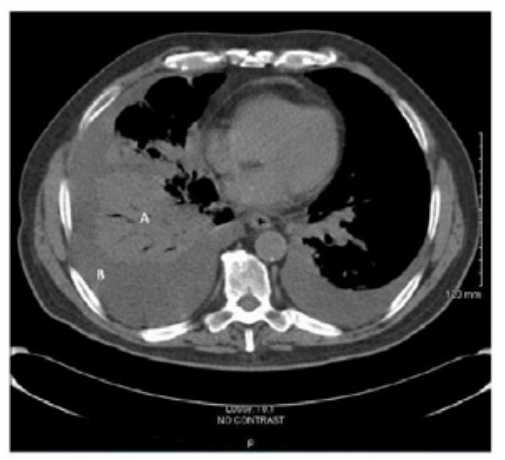

Figure 3: CT scan of chest. (A) Marks consolidation in lung. (B) Marks pleural effusion.

*Corresponding author: Shantanu Singh, Henderson Pulmonary and Sleep Medicine, 568 Ruin Creek Road, Suite 127, Henderson, NC 27536, USA, E-mail shantanu512@gmail.com

Received December 10, 2012; Accepted January 31, 2013; Published February 04, 2013

Citation: Shantanu Singh, Ashish Singh (2013) Metastasis of Prostate Cancer to Pleura. J Pulmon Resp Med 3: 135. doi:10.4172/2161-105X.1000135

Copyright: (c) 2013 Shantanu Singh, et al. This is an open-access article distributed under the terms of the Creative Commons Attribution License, which permits unrestricted use, distribution, and reproduction in any medium, provided the original author and source are credited. 
of six thoracentesis done over a period of 1 month. Therefore, a mediastinoscopic lymph node biopsy to confirm the suspected diagnosis of small cell lung cancer and a Video-Assisted Thoracoscopic Surgery (VATS) pleurodesis to address the recurrent right pleural effusion was undertaken. VATS demonstrated multiple tumor nodules on the visceral and pleural surfaces (Figure 4). Biopsies of both mediastinal lymph node and pleural nodules were reported to show metastatic prostatic adenocarcinoma with positive PSA stains on specimens from both sites (Figures 5 and 6). Furthermore, review of slides of patient's initial prostate cancer diagnosis revealed histologic and immunohistochemical features similar to the present biopsies from mediastinal lymph node and pleural nodules.

Several months prior to the above pulmonary presentation, patient was diagnosed with recurrence of prostate cancer and had been started on Lupron injections. But his disease was refractory to hormone treatment as his follow-up bone scan and pelvic CT scan revealed newly present foci of activity at T5 and right anterior sixth rib concerning for metastatic disease on bone scan and a $2.6 \mathrm{~cm}$ rim-enhancing soft tissue nodule in the pelvic sidewall and new retroperitoneal lymph nodes in the aortocaval station measuring up to $1.8 \mathrm{~cm}$ on pelvic CT. At
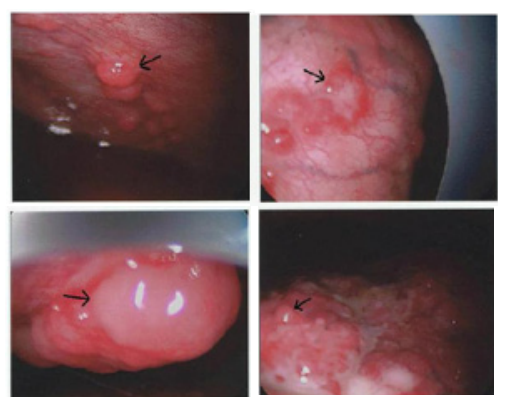

Figure 4: Black arrows show pulmonary nodules during VATS procedure.

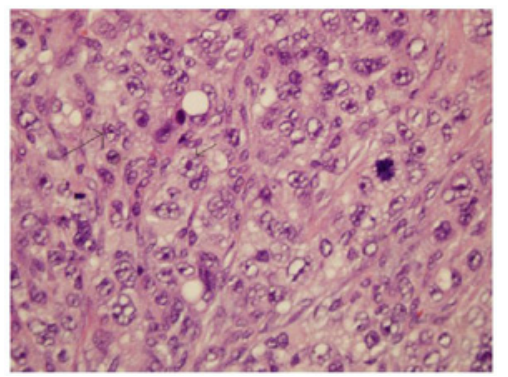

Figure 5: $\mathrm{H}$ \& $\mathrm{E}$ stain of pleural biopsy. Black arrows showing adenocarcinoma.

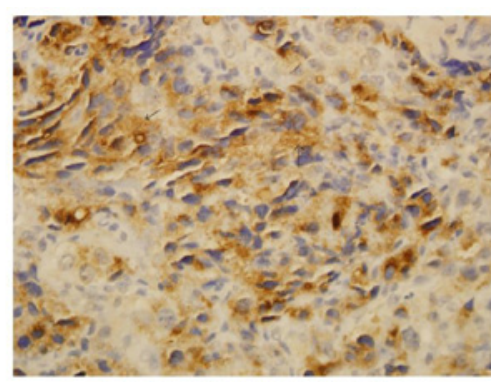

Figure 6: Black arrows pointing to positive PSA stain in pleural nodules biopsy. the time patient developed above pulmonary presentation, intravenous bisphosphonate and systemic chemotherapy were being considered for prostate cancer treatment but were held to allow patient to recover from "pneumonia".

\section{Discussion}

Prostatic carcinoma has a well-recognized pattern of metastatic disease, most frequently involving the axial skeleton and local nodes $[1,2]$. Pleural involvement is the second rarest site after the adrenals among soft tissue metastasis2. Malignant pleural effusion has been found in association of prostate cancer but it is very rare [3,4]. Pleural effusion as determined by autopsy ranged from 2.3 to $5 \%$ [3].

With an increase in the life-expectancy, the prevalence of prostate cancer is expected to increase and it is important for physicians to be aware of the diverse presentations of advanced metastatic prostate cancer. This case demonstrates this challenge. Patient's treatment for metastatic prostate cancer was put on hold until initially he could recover from "pneumonia" and later CT chest report and bronchoscopic biopsy report leading to a diagnosis of "primary lung cancer". Diagnosis of pleural metastasis was really made accidentally as the reason for doing VATS was pleurodesis for recurrent pleural effusions and not because pleural metastasis was suspected. With report of this case, we hope to raise the awareness of prostate cancer's metastasis to thorax. Early detection is likely to lead to early treatment and improvement in outcomes.

At present, hormonal treatment is recommended for lung metastases from prostate cancer [5]. In case of androgen refractory prostate cancer, surgical resections of the metastasis, chemotherapy or fractionated intraluminal iridium ${ }^{193}$ high dose rate brachytherapy have been reported to be effective [6].

\section{Consent}

Informed consent was obtained from the patient for publication of this case report and any accompanying images.

\section{References}

1. Murphy M, Johnston C, Whelan P, Rider L, Lloyd SN (1999) Changing trends in prostatic cancer. BJU Int 83: 786-791.

2. Bubendorf L, Schöpfer A, Wagner U, Sauter G, Moch H, et al. (2000) Metastatic patterns of prostate cancer: an autopsy study of 1,589 patients. Hum Pathol 31: $578-583$

3. Renshaw AA, Nappi D, Cibas ES (1996) Cytology of metastatic adenocarcinoma of the prostate in pleural effusions. Diagn Cytopathol 15: 103-107.

4. Rapoport AH, Omenn GS (1968) Dermatomyositis and malignant effusions: rare manifestations of carcinoma of the prostate. J Urol 100: 183-187.

5. Gerogianni I, Gravas S, Papadopoulos D, Terzis A, Nakou M, et al. (2008) Endobronchial metastasis from prostate cancer. Int Urol Nephrol 40: 961-964.

6. Stranzl H, Gabor S, Mayer R, Prettenhofer U, Wurzinger G, et al. (2002) Fractionated intraluminal HDR 192/r brachytherapy as palliative treatment in patients with endobronchial metastases from non-bronchogenic primaries. Strahlenther Onkol 178: 442-445. 